\title{
Ethereum and the SEC: Why Most Distributed Autonomous Organizations are Subject to the Registration Requirements of the Securities Act of 1933 and a Proposal for New Regulation
}

Tiffany L. Minks

managing.editor-5@tamulawreview.org

Follow this and additional works at: https://scholarship.law.tamu.edu/lawreview

Part of the Business Administration, Management, and Operations Commons, Business and Corporate Communications Commons, Contracts Commons, Corporate Finance Commons, Entrepreneurial and Small Business Operations Commons, Finance and Financial Management Commons, Internet Law Commons, Legislation Commons, Other Business Commons, Other Law Commons, Rule of Law Commons, and the Securities Law Commons

\section{Recommended Citation}

Tiffany L. Minks, Ethereum and the SEC: Why Most Distributed Autonomous Organizations are Subject to the Registration Requirements of the Securities Act of 1933 and a Proposal for New Regulation, 5 Tex. A\&M L. Rev. 405 (2018).

Available at: https://doi.org/10.37419/LR.V5.I2.5

This Comment is brought to you for free and open access by Texas A\&M Law Scholarship. It has been accepted for inclusion in Texas A\&M Law Review by an authorized editor of Texas A\&M Law Scholarship. For more information, please contact aretteen@law.tamu.edu. 


\title{
COMMENT
}

\section{ETHEREUM AND THE SEC: WHY MOST DISTRIBUTED AUTONOMOUS ORGANIZATIONS ARE SUBJECT TO THE REGISTRATION REQUIREMENTS OF THE SECURITIES ACT OF 1933 AND A PROPOSAL FOR NEW REGULATION}

\author{
by: Tiffany L. Minks*
}

\begin{abstract}
In a world full of new technology, the risk of fraud is constantly increasing. In the securities industry, this risk existed long before the use of technology. Congress enacted the Securities Act of 1933 to combat the risk of fraud and misrepresentation in the sale of securities. By requiring full disclosure, investors have the opportunity to make informed decisions prior to investing. However, Distributed Autonomous Organizations ("DAOs"), through the use of blockchains and smart-contracts, engage in the sale of securities without fully disclosing the risks or complying with the registration requirements of the Securities Act of 1933. Compliance with the burdensome requirements of registration, however, would destroy this new technology and method of conducting business. To avoid this set-back, Congress must amend the registration requirements to provide an exemption for DAOs. This exemption, although reducing current registration burdens, must still require DAOs to disclose certain information, thereby ensuring investors are informed prior to investing. Furthermore, due to the unique nature of the blockchain, smartcontract, and DAOs, Congress must impose a fiduciary duty on the creators of DAOs to ensure compliance with the disclosure requirements. Further, Congress should consider the allowance of burden-shifting following the initial crowdsale.
\end{abstract}

\section{TABle of Contents}

I. IntRoduction............................. 406

II. Bitcoin, the BlockChain, AND the Expansion of Blockchain Technology...................... 409

III. What is Ethereum? ........................ 410

A. A Brief History of Ethereum .................. 411

B. Ether............................... 413

C. Miners: How the Blockchain is Secured ........... 413

D. Smart-Contracts ......................... 415

* J.D. Candidate, Texas A\&M University School of Law, April 2018; B.B.A. in Management, magna cum laude, Texas A\&M University-Central Texas, 2013; M.B.A. with a concentration in Finance, magna cum laude, Houston Baptist University, 2014. The Author would like to acknowledge and thank her faculty advisor, Mark Burge, and her husband, Shane Minks, for their invaluable support and guidance through the publication of this Article.

DOI: https://doi.org/10.37419/LR.V5.I2.5 
IV. Distributed Autonomous Organizations ......... 416

A. Crowdfunding............................ 417

B. "The DAO" and its Breach .................. 418

C. The Recent Surge in the Use of Ethereum and DAOs................................. 420

V. The Securities Act of 1933, Issuers, AND InVESTMEnt Contracts ........................ 421

A. Investment of Money....................... 422

B. Common Enterprise......................... 423

C. Expectation of Profits ....................... 424

D. Efforts of Others ........................ 424

E. SEC Release No. 81207 ...................... 425

VI. A Brief Overview of Current Registration Requirements ................................ 426

VII. The Future of DAOs Due to the Effects of Regulation ................................. 427

A. Registration Requirements for Issuer of Securities ... 427

B. Why Regulation is Necessary and Actions Taken by Congress .................................... 429

C. Proposal for New Regulation .................. 430

1. Responsibility for Required Disclosures ....... 431

2. Required Disclosures ................... 433

a. Disclosure of the Creator's Name ......... 433

b. Disclosure of the DAOs Purpose ......... 433

c. Disclosure of the Smart-Contract's Terms ... 434

d. Third-Party Service Provider Disclosure .... 434

e. Disclosure of Risks ..................... 435

f. Financial Disclosures ................... 436

3. Disclosures Following the Crowdsale ........ 436

VIII. Conclusion ................................. 437

\section{INTRODUCTION}

Imagine an organization that is fully controlled by its shareholders. There are no directors, officers, or managers. Shareholders have the power to propose projects, which they then collectively choose, through a vote, to pursue or reject. The terms of the shareholders' power are written into a self-executing, electronic-contract, also known as a "smart-contract." The contract defines, among other things, how many shareholders must vote to approve a proposal, how long the proposal remains open for voting, and the third-party service provider responsible for implementing the proposal if it is approved. Once certain terms within the contract are fulfilled, the smart-contract automatically moves to the next step without any human input required. For example, when a proposal receives the required number of votes, the project specifications are automatically sent to the third- 
party service provider for implementation, manufacturing, or distribution.

Consider, however, the potential risks associated with this type of investment. These risks include the possibility that a proposal will never be approved, resulting in the organization never making a profit; the risk that the proposal is written poorly, thereby preventing the third-party service provider from properly executing the project after approval; or the risk of a cyber-criminal hacking into the smartcontract and stealing the organization's funds.

Now, with this idea of smart-contracts in mind, think about the technological changes and advances resulting from the introduction of the first virtual currency, Bitcoin. Since the introduction of the Bitcoin, the world has been captivated by the concept of "virtual currency." 1 The United States Financial Crimes Enforcement Network ("FinCEN") has defined virtual currency as "a medium of exchange that operates like a currency in some environments, but does not have all the attributes of real currency. In particular, virtual currency does not have legal tender status in any jurisdiction."

Virtual currencies are created using distributed ledger technology, which is essentially a database that can be shared across a multitude of networks. ${ }^{3}$ Built within this database is a "blockchain," which creates a transaction ledger and allows a transaction to be verified by the network and encrypted, thereby ensuring its legitimacy. ${ }^{4}$ In simple terms, every transaction is recorded by taking information from the previous block, adding it into a new block, and inserting that new block into the chain to keep a constant and accurate record of every transaction. ${ }^{5}$

Ethereum, however, is taking the concept of virtual currency and the blockchain to a new level. In 2014, the creators of Ethereum introduced the software necessary to operate the previously discussed smart-contracts, which are built on powerful blockchains. ${ }^{6}$ Because smart-contracts are built on a blockchain, every transaction is connected, thereby ensuring accuracy and security.

1. See Nicolas Wenker, Online Currencies, Real-World Chaos: The Struggle to Regulate the Rise of Bitcoin, 19 Tex. Rev. L. \& Pol. 145, 146 (2014).

2. Fin. Crimes Enf't Network, Dep't of Treasury, Guidance: Application of FinCEN's Regulations to Persons Administering, Exchanging, or Using Virtual Currencies I (Mar. 18, 2013); see Mark Edwin Burge, Apple Pay, Bitcoin, and Consumers: The ABCs of Future Public Payments Law, 67 Hastings L. J. 1493, 1527 (2016) (describing virtual currency).

3. Gov't Office for ScI., Distributed Ledger Technology: Beyond BLOCK CHAIN, REPORT, 2016, at 5 (UK).

4. Id.; Burge, supra note 2, at 1529.

5. See What is Bitcoin Mining?, BITCOINMINING.COM, https://www.bitcoinmining .com (last visited Sept. 18, 2016) [https://perma.cc/7QQG-KTC6].

6. What is Ether, Ethereum, https://www.ethereum.org/ether (last visited Sept. 4, 2016) [https://perma.cc/B2HE-FGV8]. 
Smart-contracts operated on the Ethereum platform are funded by a new virtual currency called Ether. ${ }^{7}$ Although the possibilities of smart-contracts are not yet fully known, the concept has resulted in many successful Distributed Autonomous Organizations ("DAOs"), and the use of the platform has surged in recent months.

Generally, DAOs have no capital when created. ${ }^{8}$ After creation, they are funded through a trustless crowdsale. ${ }^{9}$ The crowdsale allows the organization to raise funds online from investors around the world, and, in return, the organization gives its members tokens. ${ }^{10}$ These tokens give the member the power to propose projects and vote, much like a shareholder in a traditional corporation. ${ }^{11}$ Based on the success of the organization, the tokens may increase in value, giving the token holder a share in the profits of the organization. ${ }^{12}$

Behind the still-incredible possibilities of Ethereum hide the unknown legal implications of the decentralized platform. Along with the well-discussed issue of regulating crypto-currencies that defy limitations and function autonomously from any governmental authority, lawmakers, lawyers, and courts must now determine the best way to regulate DAOs. ${ }^{13}$

This Article discusses why DAOs created on the Ethereum platform are issuers of securities and subject to regulation under the Securities Act of 1933. This Article also describes the capabilities and benefits of this new technology. In an effort to avoid destruction by regulation, this Article proposes an amendment to the current registration requirements. Finally, the Article provides guidance on the disclosures that Congress should avoid, disclosures that should be required, and a proposal that a fiduciary duty be placed on the creators of DAOs to ensure compliance.

Part II of this Article discusses the blockchain, how it was first introduced through the creation of Bitcoin, and how the technology has expanded into smart-contracts and other areas of the financial industry. Part III introduces the history of Ethereum, the smart-contract, and Ether ("ETH") - the cryptocurrency used to fund smart-contracts on the Ethereum platform. Part IV discusses Distributed Autonomous Organizations, the recent hack of "The DAO," and the implications of that breach. Part V explains why tokens issued by DAOs are securities under the Securities Act of 1933, with Part VI giving a brief overview of the current registration requirements under the Securities Act of 1933. Because the Article concludes that DAOs are issuers of securi-

7. Id.

8. See Kickstart a Project with a Trustless Crowdsale, ETHEREum, https://www .ethereum.org (last visited Sept. 11, 2016) [https://perma.cc/M5H8-8F5U].

9. Id.

10. See infra text accompanying notes 90-94.

11. See infra text accompanying note 100 .

12. See infra text accompanying note 99 .

13. Wenker, supra note 1, at 147. 
ties, Part VII proposes an amendment to the current registration requirements that would place a fiduciary duty on the creators of DAOs in an effort to ensure compliance with required disclosures. Furthermore, this Part discusses disclosures Congress should avoid imposing on DAOs, as well as disclosures that must be required. Part VIII is a conclusion of the Article.

\section{Bitcoin, The Blockchain, And the Expansion of BlockChain TeChNOLOGY}

"Blockchain technology continues to redefine not only how the exchange sector operates, but the global financial economy as a whole."

-Bob Greifeld, 2015 ${ }^{14}$

Through decentralized ledger technology, the blockchain has created a new, exciting opportunity for the financial industry. ${ }^{15}$ The most widely known use of blockchain technology is the Bitcoin. ${ }^{16}$ Bitcoin was introduced in 2009 as the world's first decentralized virtual currency, meaning that transactions involving the currency require no middleman such as a bank. ${ }^{17}$ Bitcoin is not legally regulated or recognized by any jurisdiction, although some jurisdictions have acknowledged it as money. ${ }^{18}$ Bitcoin transactions are recorded on a blockchain; however, the names of the individuals involved in the transaction are never recorded, thereby providing full anonymity. ${ }^{19}$

As the uses of blockchain expand beyond Bitcoin, the blockchain is proving to be beneficial in multiple industries, specifically the financial industry. For example, prior to the introduction of the blockchain, stock exchanges required a centralized clearinghouse to process certain financial transactions. ${ }^{20}$ The use of a clearinghouse requires paper records and reliance on an individual at a bank to ensure transactions

14. Philip Stafford, Banks and Exchanges Turn to Blockchain, Fin. TIMES (June 30, 2015), https://www.ft.com/content/764aed26-198a-11e5-8201-cbdb03d71480 [https:/ /perma.cc/K7SP-CYLB].

15. Id.; see Lester Coleman, How Blockchain Technology Can Benefit Many Industries Beyond Finance, CRYPTOCOINS NEws (July 3, 2016), https://www.cryptocoinsnews.com/blockchain-technology-can-benefit-many-industries-beyond-finance/

[https://perma.cc/ZT22-RT5W] (discussing the benefits of decentralized ledger technology for other industries).

16. See Gov't Office For ScI., supra note 3, at 27.

17. Tal Yelling, Dominic Aratari, \& Jose Pagliery, What is Bitcoin?, CNN Money, http://money.cnn.com/infographic/technology/what-is-bitcoin/ (last visited Jan. 6, 2017) [https://perma.cc/BD9M-NLEF].

18. Is Bitcoin Legal?, CoINDEsk, http://www.coindesk.com/information/is-bitcoinlegal/ (last visited Jan. 6, 2017) [https://perma.cc/VV6T-8XWQ]; see SEC v. Shavers, No. 4:13-CV-416, 2013 WL 4028182 (E.D. Tex. 2013).

19. Tal Yelling, Dominic Aratari, \& Jose Pagliery, Anonymity, CNN Money, http://money.cnn.com/infographic/technology/what-is-bitcoin/ (last visited Jan. 6, 2017) [https://perma.cc/9J4T-HZLR] (users Wallet ID numbers are recorded in the blockchain).

20. Stafford, supra note 14. 
are conducted timely and properly. ${ }^{21}$ This process is inefficient and produces the potential for fraud and mistake. ${ }^{22}$ Now, the use of decentralized ledger technology has eliminated the need for a centralized authority. ${ }^{23}$ All transactions can be efficiently recorded on a blockchain, eliminating the need for paper records and removing the probability of human error. It is anticipated that the benefits of the blockchain will soon branch out into other industries, including the legal industry. ${ }^{24}$

This Article focuses on how blockchain technology has been used to form smart-contracts, resulting in the creation of Decentralized Autonomous Organizations ("DAOs"). These organizations operate with no centralized authority - the shareholders are in complete control, and like Bitcoin transactions, their identities remain anonymous. ${ }^{25}$ Currently, the Ethereum platform is the leading software provider using the blockchain to operate smart-contracts that govern DAOs. ${ }^{26}$

\section{What is Ethereum?}

"Commerce on the Internet has come to rely almost exclusively on financial institutions serving as trusted third parties to process electronic payments.

What is needed is an electronic payment system based on cryptographic proof instead of trust, allowing any two willing parties to transact directly with each other without the need for a trusted third party."

-Satoshi Nakamoto, $2008^{27}$

Etheruem is a decentralized platform created to operate smart-contracts. ${ }^{28}$ Decentralized platforms do not have a single administrator, but instead operate on a blockchain, which is a type of distributed ledger. ${ }^{29}$ A distributed ledger is a consensus of digital data that spread

21. See Gov't Office for ScI., supra note 3, at 27.

22. See id.

23. Stafford, supra note 14.

24. See generally Dennis Kennedy \& Gwynne Monahan, Lawyers Get Ready, There's a Blockchain Coming, Law Practice Today (Jan. 13, 2017), http://www.law practicetoday.org/article/lawyers-blockchain/?utm_source=January17\&utm_medium= email\&utm_campaign=January17LPTemail [https://perma.cc/F4N4-8NUZ].

25. See Build Unstoppable Applications, ETHEREum, https://www.ethereum.org (last visited Sept. 4, 2016) [https://perma.cc/M5H8-8F5U].

26. Glynn Bird, Block Chain Technology, Smart Contracts and Ethereum: What Should Block Chains and Smart Contracts be Used For?, IMB (May 19, 2016), https:// developer.ibm.com/clouddataservices/2016/05/19/block-chain-technology-smart-contracts-and-ethereum/ [https://perma.cc/VY8B-22DF].

27. Satoshi Nakamoto, Bitcoin: A Peer-to-Peer Electronic Cash System, Bitcoin, https://bitcoin.org/bitcoin.pdf (last visited Dec. 19, 2017) [https://perma.cc/QX48VQBU]; see also Wenker, supra note 1, at 147.

28. Build Unstoppable Applications, supra note 25.

29. See id. 
across many sites, countries, and institutions. ${ }^{30}$ This means that many high-powered computers around the world, called miners, operate the blockchain by adding blocks of digitally stored data to the chain. ${ }^{31}$ An example of the type of digital-data that may be included in a block is the information from a transaction whereby Ether is transferred from one user to another. ${ }^{32}$ After miners build digital data into the block, the block is stored in a linear chain, hence the term "blockchain." 33 Because each block added to the chain includes information from the previous block, the system is trustless, meaning miners will immediately become aware if other miners enter fraudulent transactions. ${ }^{34}$

Cryptography is used to ensure the security of the blockchain..$^{35}$ Cryptography is a method of encoding data to ensure the prevention of data disclosure, thereby allowing the ledger to be manipulated securely and eliminating the need for a central authority. ${ }^{36}$

\section{A. A Brief History of Ethereum}

The Ethereum platform was created by Vitalik Buterin and Dr. Gavin Wood to "enable[] developers to create markets, store registries of debts or promises, move funds in accordance with instructions given long in the past (like a will or a futures contract) and many other things that have not been invented yet, all without a middle man or counterparty risk." ${ }^{37}$ Buterin and Wood created the Ethereum Foundation to handle the legal and financial issues associated with the presale of Ether-the cryptocurrency used to fund Ethereum smartcontracts-prior to developing the necessary software to operate the platform or seeking developers, miners, or investors. ${ }^{38}$ The presale, which required the use of other cryptocurrencies to purchase Ether, was necessary for two reasons: 1) to collect money to finish development of the network; and, 2) to ensure a single, internal cryptocurrency was available for use on the network to prevent the program

30. Blockchain Technology Explained, BLOCKCHAIN TECHS., http://www.block chaintechnologies.com/blockchain-definition (last visited Sept. 4, 2016) [https://perma .cc/6ZH9-LFKM].

31. Id.

32. See id.

33. Id.

34. See id.

35. Steven Norton, CIO Explainer: What is Blockchain?, Wall St. Journal: CIO Journal (Feb. 2, 2016, 12:49 AM), http://blogs.wsj.com/cio/2016/02/02/cio-explainer-what-is-blockchain/ [https://perma.cc/KAW9-ELH7]; see Yaman Akdeniz, Cryptography \& Encryption, CYBER-RIGHTS (1996), http://www.cyber-rights.org/ crypto/cryptog.htm [https://perma.cc/RMS9-JGNR].

36. Norton, supra note 35.

37. Build Unstoppable Applications, supra note 25.

38. Id.; History of Ethereum, ETHEReum Homestead, https://ethereum-homestead.readthedocs.io/en/latest/introduction/history-of-ethereum.html (last visited Jan. 1, 2018) [https://perma.cc/7M52-UCC5]. 
from becoming bogged down by the use of multiple currencies. ${ }^{39}$ The presale was successful, netting 31,591 bitcoins, worth over $\$ 18$ million at that time, in exchange for over 60 million Ether. ${ }^{40}$ The successful presale established a network of individuals interested in the concept of Ethereum and created a foundation for the success of the organization.

Following the presale, the creators established a new organization called "ETH DEV" to manage the further development of Ethereum. ${ }^{41}$ Buterin and Wood serve as two of the three directors for ETH DEV. ${ }^{42}$ It should be noted that this structure inherently affords Buterin and Wood a degree of centralized control, as evidenced by the now not-so-uncommon hard forks addressed later in the Article. ${ }^{43}$ This control creates concerns about the actual level of decentralization on the Ethereum platform. ${ }^{44}$

During the year following the successful presale, further development and security tests were conducted on the platform. On July 30 , 2015, the first version of the program launched, known as Ethereum Frontier, and developers began writing smart-contracts. ${ }^{45}$ The second version of the program, known as Ethereum Homestead, was launched in March 2016. ${ }^{46}$ The Homestead version included upgrades that removed many risks from the Ethereum homepage. ${ }^{47}$ In order to introduce the program to non-technologically savvy users, Ethereum began releasing the third version, called Ethereum Metropolis, in 2017; the release was split into two parts, with Part B scheduled to release in early $2018 .^{48}$

39. Armand Tanzarian, Ethereum Raises 3,700 BTC in First 12 Hours of Ether Presale, The Cointelegraph (July 23, 2014), https://cointelegraph.com/news/ethereum-raises-3700-btc-in-first-12-hours-of-ether-presale [https://perma.cc/A4M39H4R].

40. History of Ethereum, supra note 38.

41. Id.

42. Id.

43. See infra text accompanying notes $110,114-25$.

44. Bitcoin Australia Team, Four Lessons to Learn from the Ethereum Hard Fork, BITCOIN.COM.AU (Sept. 23, 2016), https://bitcoin.com.au/page/four-lessons-learnethereum-hard-fork/ [https://perma.cc/Z5NC-R5W6].

45. History of Etheruem, supra note 38.

46. The Homestead Release, Ethereum Homestead, http://ethdocs.org/en/latest/ introduction/the-homestead-release.html (last visited Dec. 19, 2016) [https://perma.cc/ JG7Z-53WZ].

47. The Ethereum Releases of Frontier, Homestead, Metropolis and Serenity, CRYPTOCOMPARE, https://www.cryptocompare.com/coins/guides/the-ethereum-releases-of-frontier-homestead-metropolis-and-serenity/ (last visited Dec. 19, 2016) [https://perma.cc/K6S6-WLX2].

48. Id.; Alyssa Hertig, Toward Metropolis: After Blockchain Repairs, Ethereum Looks Ahead, CoInDesk (Dec. 8, 2016, 7:30 PM), http://www.coindesk.com/metropolis-ethereum-blockchain-attacks-look-forward/ [https://perma.cc/SVN7-EKPD]; Simple Crypto, Ethereum Metropolis Update Could be Split into 2 Forks, Medium (July 14, 2017), https://medium.com/@SimpleCrypto/ethereum-metropolis-could-be-splitinto-2-forks-c4de5c7ad43e [https://perma.cc/9AD6-BBT2]; Justin Danneman, A Sim- 


\section{B. Ether}

Ether is the virtual medium of exchange used on the Ethereum platform, also known as "the crypto-fuel for the Ethereum network." ${ }^{9}$ The cryptocurrency is traded on various virtual currency exchanges and is denominated as "ETH." ${ }^{50}$ Both developers of applications and miners on the network are paid in Ether. ${ }^{51}$ The most common way to obtain Ether, other than mining, is to purchase Bitcoin on an exchange and trade it for Ether. ${ }^{52}$ Therefore, Ether is comparable to stock issued to developers and miners that can be traded for other virtual currencies on a secondary market. Tokens, which are later discussed in the Article, should not be confused with Ether. ${ }^{53}$

\section{Miners: How the Blockchain is Secured}

Following the launch of Ethereum Frontier, at which time smartcontracts funded by Ether became operational, developers recognized the need to ensure the blockchain remained secure and functional. Virtual currency is susceptible to electronic counterfeiting, resulting in a potential "double-spending" problem. ${ }^{54}$ "Double-spending" occurs when a digitally signing party spends the electronic currency more than one time, thereby causing a multitude of problems. ${ }^{55}$ Seeking to combat this risk, miners joined the network to confirm transactions. ${ }^{56}$

Mining is the decentralized process by which computers running the Ethereum software confirm transactions through a "proof-of-work" problem. ${ }^{57}$ Successful completion of the "proof-of-work" problem results in a new block being added to the blockchain. ${ }^{58}$ The mining process involves confirming the validity of an Ether transaction, bundling the transaction into a block, and inserting the block into the blockchain. ${ }^{59}$ Once the block is inserted into the blockchain, the miner

ple Guide to the Ethereum Metropolis Upgrade, Souawker (Oct. 2, 2017), https:// squawker.org/technology/a-simple-guide-to-the-ethereum-metropolis-upgrade/

[https://perma.cc/J2NW-4UCR].

49. What is Ether, supra note 6.

50. Exchange Cryptocurrency at the Best Rate, Changelly, https://changelly.com/ exchange/BTC/ETH/1?ref_id=coinmarketcap (last visited Dec. 20, 2016) [https://per ma.cc/Q7G8-YW4V].

51. What is Ether, supra note 6.

52. Jordan Tuwiner, How to Buy Ethereum / Ether Classic, Buy BitcoIn WorldwIDE (July 13, 2017), https://www.buybitcoinworldwide.com/ethereum/buy/ [https:// perma.cc/PE39-VNZY].

53. See generally infra text accompanying notes 89-95.

54. Burge, supra note 2, at 1529.

55. Id.

56. History of Ethereum, supra note 38.

57. See Burge, supra note 2, at 1530; Ethereum (Ether) Mining, BITCOINMINING .COM, https://www.bitcoinmining.com/ethereum-mining/ (last visited Mar. 11, 2017) [https://perma.cc/T9WS-7YRZ].

58. What is Bitcoin Mining?, BITCOINMINING.COM, https://www.bitcoinmining.com (last visited Sept. 18, 2016) [https://perma.cc/7QQG-KTC6].

59. Id. 
answers a "proof-of-work" problem, thereby confirming that the new block was costly and time-consuming. ${ }^{60}$ This process ensures that the Ether paid to a miner has been earned. ${ }^{61}$

Other than the initial presale, mining is currently the only method to create new Ether, although it can be bought and sold on secondary virtual currency markets. ${ }^{62}$ Furthermore, the hardware and electricity costs required to mine are very expensive, thereby limiting the number of miners, as well as the amount of Ether paid for mining. ${ }^{63}$

When bundling the transaction into a block, the miner takes information from two blocks and turns it into a mathematical formula known as a "hash." ${ }^{64}$ Each hash contains properties found in the previous block, which allows the new block to connect within the blockchain. ${ }^{65}$ If a block is ever corrupted, or a fake transaction entered by tampering with information already stored in a block, the hash within a block would be incorrect, thereby preventing new blocks from connecting to the blockchain. ${ }^{66}$ The failure to connect serves as an alert of the fraudulent transaction, giving the miners the opportunity to halt all future transactions and to protect the blockchain from the effects of the fraudulent activity. ${ }^{67}$

With the introduction of Ethereum Metropolis, Ethereum began switching from the "proof-of-work" system to a "proof-of-stake" system. ${ }^{68} \mathrm{~A}$ "proof-of-stake" system requires miners to use their Ether as collateral in verifying transactions. ${ }^{69}$ This switch will further secure the blockchain by requiring miners to take a stake in the verification of blocks and effectively move the entire process away from mining and into validating transactions. ${ }^{70}$ Additionally, it will open up the validation process to those on the network who lack the funds and skill re-

60. Id.

61. Id.

62. Charles Bovaird, What Investors Should Know Before Trading Ether, CoInDesk (May 8, 2016, 3:12 PM), http://www.coindesk.com/what-to-know-tradingethereum/ [https://perma.cc/NF68-JELU].

63. Danny Bradbury, Can Hobbyist Bitcoin Miners Still Make a Buck?, CoInDesk (Nov. 8, 2014, 3:30 PM), http://www.coindesk.com/can-hobbyist-bitcoin-miners-stillmake-buck/ [https://perma.cc/Z253-TG47].

64. How Bitcoin Mining Works, CoinDesk (Dec. 22, 2014), http://www.coindesk .com/information/how-bitcoin-mining-works/ [https://perma.cc/NZU8-9VN3].

65. Id.

66. Id.

67. Id.

68. Jim Manning, Proof-of-Work v. Proof-of-Stake Explained, ETHNews (Nov. 2, 2016, 8:25 PM), https://www.ethnews.com/proof-of-work-vs-proof-of-stake-explained (last visited Dec. 19, 2016) [https://perma.cc/P5YQ-M4SE]; Prableen Bajpai, Ethereum To Adopt Proof-of-Stake, Investopedia (May 1, 2017, 10:19 AM), http://www .investopedia.com/news/ethereum-adopt-proofofstake/ [https://perma.cc/J49PDEZC].

69. Manning, supra note 68.

70. Id. 
quired to complete the "proof-of-work" problem, thereby increasing the blockchain's decentralization. ${ }^{71}$

\section{Smart-Contracts}

"What is the meaning and purpose of 'security'? How does it relate to the relationships we have? I argue that the formalizations of our relationships - especially contracts - provide the blueprint for ideal security."

—Nick Szabo, $1997^{72}$

A smart-contract is essentially a computer program code capable of facilitating, implementing, and enforcing agreements using blockchain technology. ${ }^{73}$ Because the terms of the agreement are preprogrammed and capable of self-execution ${ }^{74}$ the program is decentralized and allows for the elimination of third-parties generally needed to ensure the agreement is executed and enforced. ${ }^{75}$

While traditional contracts are generally drafted by lawyers or transacting parties themselves, computer programmers create smartcontracts by using smart-contract development tools and programming code. ${ }^{76}$ Like traditional contracts, the code sets out the rules for the contract, the obligations of each party, and the benefits and consequences that may result in various circumstances. ${ }^{77}$ The difference, however, is that the programming code automatically executes when a term within the contract is (or is not) satisfied. ${ }^{78}$

One of the greatest benefits of smart-contracts is the ability to selfexecute and self-enforce through the programming within the software. ${ }^{79}$ Delays and failures to perform certain specified aspects of the contract can be avoided. To provide context, the execution of contracts dependent on external events, such as financial derivatives that

71. Id. (currently the computer hardware needed to complete the "proof-of-work" problem is very expensive).

72. Nick Szabo, The Idea of Smart Contracts, Nick Szabo's PAPERs And Concise TutORIALs, http://www.fon.hum.uva.nl/rob/Courses/InformationInSpeech/CDROM/ Literature/LOTwinterschool2006/szabo.best.vwh.net /idea.html (last visited Mar. 10, 2017) [https://perma.cc/C8F8-6TXR].

73. Smart Contracts Explained, BlockCHAIN Techs., http://www.blockchaintech nologies.com/blockchain-smart-contracts (last visited Sept. 4, 2016) [https://perma.cc/ 7ZHB-DLR9].

74. Id.

75. See id.

76. Id.

77. $I d$.

78. $I d$.

79. See Monetary and Capital Mkts., Legal, and Strategy and Policy Review Dep'ts, Int'l Monetary Fund, Virtual Currencies and Beyond: InITIAL Considerations (2016), http://www.imf.org/external/pubs/ft/sdn/2016/sdn1603 .pdf [https://perma.cc/3BU8-TXKW]. 
are traded when reaching a specified price, will greatly benefit from the decentralization of a smart-contract. ${ }^{80}$

Although the potential benefits of smart-contracts are significant, they are also susceptible to noteworthy risk. When individuals invest in organizations operated by a smart-contract, as discussed in Section IV.A, it is often unclear what will come of the investment and what level of risk is associated with the investment. This creates the potential for fraud and financial loss, which will be discussed in Section IV.B.1.

\section{Distributed Autonomous Organizations}

The idea of a rigid organization [sic] or corporation will evaporate and left will be the true essence of human interaction patterns, policed only by openness and information-theoretic mathematics . . . strict legality of the emergent behavior will become increasingly less relevant as it becomes drastically pluralistic and unpoliceable with no entity, legal or otherwise, coordinating it or profiting from it.

-Gavin Wood, $2015^{81}$

Smart-contracts operating on the Ethereum network allow for the creation of a new concept known as Distributed Autonomous Organizations ("DAOs"). ${ }^{82}$ The operational requirements and structure of DAOs are built into a smart-contract through the codification of rules and decision-making, thereby eliminating the need for traditional contracts and documentation. ${ }^{83}$ The creation of a DAO results in a structure requiring no centralized control, such as officers or directors. ${ }^{84}$ David Seigel explained the concept most clearly:

A group of people write the smart contracts (programs) that will run the organization. There is an initial funding period, in which people add funds to the DAO by purchasing tokens that represent ownership - this is called a crowdsale, or an initial coin offering (ICO) - to give it the resources it needs. When the funding period is over, the DAO begins to operate. People then can make proposals to the DAO on how to spend the money, and the members who have bought it can vote to approve these proposals. ${ }^{85}$

When an investor initially invests in a DAO, there is no indication as to how or where their money will be spent. ${ }^{86}$ It is essentially a blind

80. Id.

81. Gavin Wood, Bazaar Services, Ethereum Blog (Apr. 5, 2015), https:// blog.ethereum.org/2015/04/05/bazaar-services/ [https://perma.cc/ZKT3-2DLJ].

82. David Siegel, Understanding The DAO Attack, CoIndesK (June 25, 2016, 4:00 PM), http://www.coindesk.com/understanding-dao-hack-journalists/ [https://perma.cc/ DR8G-9CT3].

83. Id.

84. Id.

85. Id.

86. See id. 
investment. ${ }^{87}$ Following investment, all investors in the DAO can propose how the money should be spent, followed by a vote. ${ }^{88}$ If and when a proposal is approved, a third-party service provider develops the product or service. ${ }^{89}$

\section{A. Crowdfunding}

DAOs raise capital through a "crowdsale." 90 Basically, a crowdsale is an Initial Public Offering ("IPO") conducted on the day an organization is formed, or sometimes prior to the formation of the organization. ${ }^{91}$ However, instead of the organization issuing stock in exchange for money, DAOs issue what are called "equity tokens" ("tokens"). ${ }^{92}$ In order to purchase these tokens, investors must first convert a recognized currency into Ether, and then use that Ether to purchase tokens. ${ }^{93}$ The governance of tokens, such as how many tokens may be issued (compare to authorized shares) ${ }^{94}$ is built into the smart-contract governing the DAO. ${ }^{95}$

Tokens, like stock, give the token holder a piece of control over the organization. ${ }^{96}$ Token holders are entitled to revenue sharing or transaction fees, which can be compared to dividends in a traditional corporation. ${ }^{97}$ Additionally, token holders generally have the right to vote on proposals concerning how the organization's money will be used. ${ }^{98}$

To further illustrate the comparison of DAOs to corporations, an organization's founders issue themselves a pre-defined number of eq-

87. Id.

88. Id.

89. See DAO, SLOCK.IT, https://web.archive.org/web/20160621022411/https:// slock.it/dao.html (last visited Dec. 21, 2016) [https://perma.cc/GR3Z-5CMP] (noting that token holders have the power to elect a new service provider based on the terms written into the smart-contract).

90. See Demian Brener, On Tokens and Crowdsales: How Startups Are Using Blockchain to Raise Capital, CoINDEsk (Aug. 20, 2016, 5:31 PM), http://www.coindesk .com/tokens-crowdsales-startups/ [https://perma.cc/SF87-2ZPS].

91. See id.; see also Kickstart a Project with a Trustless Crowdsale, supra note 8.

92. Brener, supra note 90.

93. Andrew Hinkes, The Law of the DAO, CoinDesk (May 19, 2016, 4:15 PM), http://www.coindesk.com/the-law-of-the-dao/ [https://perma.cc/A99X-795L].

94. Authorized shares are the maximum number of common shares a corporation may legally issue. The number of authorized shares must be included in the Articles of Incorporation when the corporation is formed. Kesavan Balasubramaniam, What is Authorized Stock?, INVESTOPEDIA, http://www.investopedia.com/ask/answers/06/auth orizedshares.asp (last visited Dec. 19, 2016) [https://perma.cc/9H5P-YEPF].

95. Brener, supra note 90.

96. Id. Stockholders are owners of the company and therefore have certain rights and control associated with that ownership. See Martin Tillier, What is a Dividend?, NASDAQ (Aug. 20, 2013, 5:31 PM), http://www.nasdaq.com/article/what-is-a-dividendcm269103 [https://perma.cc/Z8EW-P2FJ].

97. Brener, supra note 90; see Tillier, supra note 96.

98. Brener, supra note 90. 
uity tokens when writing the smart-contract. ${ }^{99}$ This is comparable to officers and directors issuing themselves a pre-defined number of shares during the IPO process, also known as a "Direct Share" program. ${ }^{100}$ However, unlike traditional IPO's that are marketed to potential significant investors - such as large banks - anyone, anywhere, can invest in a DAO's crowdsale, unless restricted by the smart-contract. ${ }^{101}$ Therefore, these organizations are essentially allowed to act as a corporation through stock issuance without complying with the filing requirements or the contractual and tortious duties imposed on a Corporation. ${ }^{102}$

\section{B. "The DAO" and Its Breach}

On April 30, 2016, slock.it, a German startup company, launched a crowdsale for its organization called "The DAO," not to be confused with a DAO in general. ${ }^{103}$ During the twenty-eight-day crowdsale period, The DAO raised a record breaking $\$ 150$ million from over 11,000 members. ${ }^{104}$

Following The DAO's crowdsale, a "recursive call" was found in the smart-contract operating The DAO. ${ }^{105}$ A recursive call occurs when a token holder sells their interest in a DAO by selling back tokens, in exchange for Ether, and the account balance fails to update until the account holder ends the transaction. ${ }^{106}$ Therefore, after a token holder has sold all of his tokens for Ether, it is possible to continue selling The DAO tokens in exchange for more Ether because the account balance does not update until the entire transaction is complete. ${ }^{107}$ To illustrate what could happen, imagine withdrawing $\$ 20$ out of an ATM. ${ }^{108}$ You only have $\$ 20$ in your account, but after the cash is dispensed the machine asks if you would like to make another transaction. ${ }^{109}$ By clicking "yes," you withdraw another $\$ 20 .{ }^{110}$ Although

99. Id.

100. Anna T. Pinedo \& James R. Tanenbaum, Frequently Asked Questions About Initial Public Offerings, MoFo Jumpstarter (2016), https://media2.mofo.com/documents/faq-ipos.pdf [https://perma.cc/86J7-YVBL].

101. Brener, supra note 90.

102. See infra text accompanying notes $110-113$ (who is held accountable when things go wrong? The Author encourages and invites others to research and write on this topic).

103. See Siegel, supra note 82.

104. Id.

105. Id.

106. The DAO, The Hack, The Soft Fork and The Hard Fork, CryptoCompare (Nov. 18, 2016, 11:55 AM), https://www.cryptocompare.com/coins/guides/the-dao-thehack-the-soft-fork-and-the-hard-fork/ [https://perma.cc/4NHM-GVVZ].

107. Id.

108. See id.

109. See id.

110. See id. 
there is no money left in the account, this process could go on until the account holder selects "no," effectively ending the transaction. ${ }^{111}$

Although The DAO creators assured token holders that there was no risk associated with this recursive call, voting was put on hold for the more than fifty proposals submitted by members while the issue was being addressed. ${ }^{112}$ However, on June 18, 2016, the recursive call within The DAO's smart-contract code was exploited resulting in the loss of more than 3.6 million Ether-equivalent to over $\$ 50$ million. ${ }^{113}$ The hacker executed a split proposal, which resulted in the payment of extra Ether and the creation of a new child DAO, which was essentially a new DAO created by the hacker to which the stolen Ether was diverted. ${ }^{114}$ Furthermore, the split proposal gave the hacker control over both the child DAO and the stolen funds. ${ }^{115}$ As Ether holders learned of the attack, the price of Ether dropped from $\$ 20$ to less than $\$ 13 .{ }^{116}$

Following the loss of $\$ 50$ million, the looming question was "what can investors do to get their money back?" The Ethereum network suggested, and after much dissent, implemented a hard fork in the blockchain. ${ }^{117}$ Basically, the hard fork resulted in erasing all transactions after the attack and creating a new blockchain that was identical to the Ethereum blockchain prior to the attack. ${ }^{118}$ However, the Ethereum network, nor The DAO creators, experienced any ramifications for the inadequately maintained software. ${ }^{119}$ Although some of the stolen money was returned to defrauded investors, this hack is an example of the risks associated with DAOs and the significant need for regulation. ${ }^{120}$

In October 2016, the Ethereum network announced two additional hard forks in the blockchain due to slow transactions and network

111. See id.

112. See Siegel, supra note 82.

113. See id.; Klint Finley, A $\$ 50$ Million Hack Just Showed That The DAO Was All Too Human, Wired (June 18, 2016, 4:30 AM), https://www.wired.com/2016/06/50-million-hack-just-showed-dao-human/ [https://perma.cc/DKD5-HNUC].

114. Drew Hinkes, A Legal Analysis of the DAO Exploit and Possible Investor Rights, Bitcoin Magazine (June 21, 2016, 11:57 PM), https://bitcoinmagazine.com/ articles/a-legal-analysis-of-the-dao-exploit-and-possible-investor-rights-1466524659 [https://perma.cc/8WMF-3L8P].

115. Id.

116. See Siegel, supra note 82.

117. Charles Boovaird, Can Two Ethereum Markets Co-Exist, CoinDesk (Aug. 21, 2016, 12:42 PM), http://www.coindesk.com/can-two-ethereum-markets-co-exist/ [https://perma.cc/9RXY-A5R9].

118. Id.

119. See Siegel, supra note 82.

120. See Michael del Castillo, Ethereum Executes Blockchain Hard Fork to Return DAO Funds, CoInDesk (July 20, 2016, 3:23 PM), http://www.coindesk.com/ethereumexecutes-blockchain-hard-fork-return-dao-investor-funds/ [https://perma.cc/BZ96CYYN]. 
issues. ${ }^{121}$ Although they were not the result of another breach, they were signs of major weaknesses in the network. Furthermore, a fourth hard fork was completed in November 2016 to further secure the network from potential attacks and to delete empty accounts left by the initial attacker. ${ }^{122}$

\section{The Recent Surge in the Use of Ethereum and DAOs}

Prior to 2017, the concept of Ethereum was unheard of by most people. In the past year, however, with the increased use of cryptocurrency and increasing value of Ether, knowledge and use of the Ethereum platform has expanded.

Recently, a company called LocalCoinATM introduced Ethereum support for its ATMs in Toronto, Canada. ${ }^{123}$ A similar ATM was introduced in 2017 in San Mateo, CA, allowing users to convert their fiat currency into Ether. ${ }^{124}$ In the future, these ATMs may allow a user to vote on resolutions or purchase items. ${ }^{125}$

During the summer of 2017, post offices in Austria began offering Ether in exchange for cash. ${ }^{126}$ Approximately 1,800 branches are offering this service, and users are given a code to upload the purchased Ether into the user's digital wallet. ${ }^{127}$

More notably, following a meeting between Russian President Vladimir Putin and Ethereum-founder Vitalik Buterin, Russian banks have begun to use an Ethereum-based blockchain for payment transactions. ${ }^{128}$ By mid-2018, banks intend to use the platform to record mortgages. ${ }^{129}$

What does this mean for Ethereum in the U.S. market? Regulators must pay attention to the usefulness of the blockchain and the growing popularity of cryptocurrency, meaning that regulators must do

121. Alyssa Hertig, So, It Looks Like Ethereum is Going to Have to Fork Again. . ., CoInDesk (Oct. 12, 2016, 10:55 PM), http://www.coindesk.com/so-it-looks-like-ethereum-is-going-to-have-to-fork-again/ [https://perma.cc/73JC-TLCM].

122. See JP Buntinx, Fourth Ethereum Hard Fork is Called Spurious Dragon, NewsBTC (Nov. 18, 2016, 2:15 PM), http://www.newsbtc.com/2016/11/18/fourthethereum-hard-fork-called-spurious-dragon/; Hertig, supra note 121.

123. Jordan Pearson, Toronto Just Got Its First Ethereum ATMs, Motherboard (Aug. 15, 2017, 10:05 AM), https://motherboard.vice.com/en_us/article/7xxbwz/toronto-just-got-its-first-ethereum-atms [https://perma.cc/K8MV-HHS4].

124. See First Ether ATM announced, SEBFOR, http://sebfor.com/first-ether-atm-announced/ (last visited Aug. 15, 2017) [https://perma.cc/KR4A-JLBD].

125. Id.

126. Lester Coleman, Austrian Post Offices Sell Bitcoin, Ethereum and More for Cash, CRYPTOCOINSNEws (July 18, 2017), https://www.cryptocoinsnews.com/post-offices-in-austria-sell-cryptocurrencies-for-cash/ [https://perma.cc/8WWZ-J6B2].

127. Id.

128. Lester Coleman, Russian Bank Consortium Uses Ethereum-Based Ledger as Government Signals Support, CRYPTOCOINSNEws (Mar. 8, 2017), https://www.crypto coinsnews.com/russian-bank-consortium-uses-ethereum-based-ledger-as-governmentsignals-support/ [https://perma.cc/BU73-Z6TY].

129. $I d$. 
their job-acknowledge the shift and regulate before Ethereum, smart-contracts, and cryptocurrencies become commonly used items capable of extreme misuse and fraud.

\section{The Securities Act of 1933, Issuers, AND INVESTMENT CONTRACTS}

Without doubt, certain aspects of DAOs will be beneficial to many industries. However, given the current lack of enforced regulation, they are also tools that companies may use to dodge securities laws and commit fraud. Investors have the right to know what they are investing in, regardless of the level of risk, and serious penalties are imposed on entities that fail to provide investors with material information. ${ }^{130}$

The Securities Act of 1933 (the "Securities Act") was enacted to protect investors from misrepresentations, omissions, and fraud. ${ }^{131}$ In furtherance of this purpose, the Securities Act requires issuers to disclose the risks of the business along with other information concerning the securities. The means used to accomplish these goals include the registration of securities. ${ }^{132}$ Before an issuer may offer to sell securities to investors, it must file a registration statement with the SEC. ${ }^{133}$ Otherwise, the issuer is in violation of the Securities Act. ${ }^{134}$

This Article argues that the tokens issued by DAOs are securities, and therefore DAOs are issuers. An issuer of a security is defined as "every person who issues or proposes to issue any security." 135 Issuers may offer or sell many types of securities to investors, but the most relevant type of security in the DAO context is an investment contract. ${ }^{136}$

130. What We Do, U.S. SeC. AND ExCH. Comm'n, https://www.sec.gov/about/ whatwedo.shtml (last visited Jan. 29, 2018) [https://perma.cc/3MQK-5D59].

131. See The Laws That Govern the Securities Industry, U.S. SEC. AND Exch. Comm'N, https://www.sec.gov/about/laws.shtml (last visited Mar. 10, 2017) [https://per ma.cc/ZL62-UE29].

132. Id.

133. Securities Act of $1933 \S 5(c), 15$ U.S.C.A. $§ 77 \mathrm{e}(\mathrm{c})$ (Westlaw through Pub. L. No. 115-90).

134. See The Laws That Govern the Securities Industry, U.S. SEC. AND Exch. Comm'N, https://www.sec.gov/about/laws.shtml (last visited Mar. 10, 2017) [https://per ma.cc/ZL62-UE29].

135. Securities Act of $1933 \S 2(4), 15$ U.S.C.A. $\$ 77 b(a)(4)$ (Westlaw through Pub. L. No. 115-90).

136. See Securities Act of 1933 § 2(a)(1), 15 U.S.C.A. § 77b(a)(1) (Westlaw through Pub. L. No. 115-90). (A security includes "any note, stock, treasury stock, security future, security-based swap, bond, debenture, evidence of indebtedness, certificate of interest or participation in any profit-sharing agreement, collateral-trust certificate, preorganization certificate or subscription, transferable share, investment contract, voting-trust certificate, certificate of deposit for a security, fractional undivided interest in oil, gas, or other mineral rights, any put, call, straddle, option, or privilege entered into on a national securities exchange relating to foreign currency, or, in general, any interest or instrument commonly known as a 'security', or any certificate 
Based on the Howey Test established in S.E.C. Comm'n v. W.J. Howey Co., a transaction may be characterized as an investment contract when: 1) it involves an investment of money; 2) in a common enterprise; 3) with a reasonable expectation of profits; 4) to be derived solely from the efforts of others. ${ }^{137}$

\section{A. Investment of Money}

An investment of money means "the investor must have committed his assets to the enterprise in such a manner as to subject himself to financial loss." 138 Although an investor in a DAO uses Ether to make such investment, there are many reasons why this investment should still be classified as an "investment of money."

First, money is defined as "something generally accepted as a medium of exchange, a measure of value, or a means of payment."139 Federal courts have held that cryptocurrency qualifies as money because it can be "exchang[ed] for ordinary currency, acts as a denominator of value, and is used to conduct financial transactions." 140 Therefore, Ether, a cryptocurrency, is money.

Second, investors in DAOs are committing their assets, in this case Ether, to the risk of financial loss. Token holders may lose their full investment if a DAO fails to engage in projects following a crowdsale or if the projects pursued perform poorly. ${ }^{141}$ Some DAOs have acknowledged this risk of loss and provided investors with risk disclosures. ${ }^{142}$

Beyond the risk of financial loss, the essential characteristics of an investment have been defined as the receipt of profits, shares in gain, and acquiring an interest in the organization's assets. ${ }^{143}$ Through revenue sharing and transactions fees, token holders of a DAO are entitled to the receipt of the organization's profits and shares in gain. ${ }^{144} \mathrm{Be}$ cause the receipt of profits and shares in gain are dependent on the

of interest or participation in, temporary or interim certificate for, receipt for, guarantee of, or warrant of right to subscribe to or purchase, any of the foregoing.")

137. SEC v. W.J. Howey Co., 328 U.S. 293, 298 (1946); David Bollier, Distributed Collaborative Organisations: Distributed Networks \& Regulatory Frameworks (Dec. 27, 2014), http://bollier.org/sites/default/files/misc-file-upload/files/DistributedNet worksandtheLaw\%20report,\%20Swarm-Coin\%20Center-Berkman.pdf [https://per ma.cc/S9CH-ZUYB].

138. Majors v. S.C. Sec. Comm'n, 644 S.E.2d 710, 716 (S.C. 2007).

139. Money, Merriam-Webster, https://www.merriam-webster.com/dictionary/ money [https://perma.cc/3PPX-5Q4B] (last updated Dec. 3, 2017).

140. U.S. v. Faiella, 39 F. Supp. 3d 544, 545 (S.D.N.Y. 2014); SEC v. Shavers, No. 4:13-CV-416, 2013 WL 4028182 (E.D. Tex. 2013).

141. Hinkes, supra note 93.

142. Id. ("The use of The DAO's smart contract code and the Creation of [DAO tokens] carries significant financial risk.")

143. All Seasons Resorts v. Abrams, 497 N.E.2d 33, 37 (N.Y. 1986).

144. Brener, supra note 90. 
success of the organization, token holders have an interest in the organization's assets. ${ }^{145}$

Therefore, by using Ether to purchase a DAO's tokens, token holders are making an investment of money because they have committed assets to the organization in a way that subjects them to the risk of loss.

\section{B. Common Enterprise}

Through a crowdsale, DAO investors pool their money together with the hope of a return on their investment following a successful vote and implementation of a project, which is ultimately pursued by a third-party service provider. ${ }^{146}$ Three tests have been established to determine whether this activity constitutes a Common Enterprise:

- The Horizontal Commonality: exists when investors pool their contributions and "the success of individual investors depends on the success of the overall ventures." $" 147$

- The Broad Vertical Commonality: exists when the investor's profits depend on the efforts of the promoter. ${ }^{148}$

- The Narrow Vertical Commonality: exists when the "investor's profits are tied to the manager's profits." 149

The majority of circuit courts use the Horizontal Commonality test, placing a significant amount of weight on the pooling of resources resulting in the investors sharing the risks and benefits of the venture. ${ }^{150}$ Because DAOs are funded through a crowdsale and investors generally share the risks and benefits, the Horizontal Commonality test would most likely be satisfied and a court would find that the DAO is a Common Enterprise.

If the Broad Vertical Commonality or Narrow Vertical Commonality tests were applied, the Common Enterprise element of the Howey Test may not be satisfied. The tests, respectively, require a showing that the promoter is an expert and that the investors rely on that expertise, or that the investor's success or failure have a direct correlation with the success or failure of the promoter's efforts. ${ }^{151}$ Therefore, whether or not the Common Enterprise element of the Howey Test is met will depend on how the DAO is presented to investors, whether there is a showing of expertise, and whether there is a correlation of profits and losses and the promoter's efforts.

145. Id.

146. Hinkes, supra note 93.

147. Bollier, supra note 137.

148. Id

149. $I d$.

150. Ryan Borneman, Note, Why the Common Enterprise Test Lacks a Common Definition: A Look Into the Supreme Court's Decision of SEC v. Edwards, 5 U.C. DAvis Bus. L.J. 16 (2005), https://blj.ucdavis.edu/archives/vol-5-no-2/why-the-common-enterprise-test.html [https://perma.cc/6NZ2-BUMG].

151. Id. 


\section{Expectation of Profits}

The purpose of investing in a DAO is to fund future projects. ${ }^{152} \mathrm{In}$ return, the investors hope to receive dividends (in the form of revenue sharing) or transaction fees. ${ }^{153}$ Many DAOs advertise to potential investors that the DAO will pursue projects that will provide a return on investment. ${ }^{154}$ For example, The DAO marketed to its potential investors that "The DAO [] has the option to accumulate [invested] ETH to support its growth, or redistribute it to [T]he [DAO token] [h]olders as a reward." 155

Absent a hope of receiving profit from the investment, a transaction is not subject to SEC regulations. ${ }^{156}$ Profits have been defined by the court as "either capital appreciation resulting from the development of the initial investment, ... or a participation in earnings resulting from the use of investors' funds." ${ }^{" 157}$ By participating in the crowdsale and subsequently voting on proposed projects, investors are expecting their investment to appreciate in value. Furthermore, the investors are planning to participate in earnings through revenue sharing, resulting from the use of their funds to pursue projects. Therefore, it is clear that by investing in DAOs, investors are expecting to receive a profit, or "capital appreciation resulting from the development of the initial investment," in return. ${ }^{158}$

\section{Efforts of Others}

The involvement of an investor in a DAO following the initial investment is limited to voting. If the investors had more involvement in the management, they would be considered general partners. ${ }^{159}$ When an investor uses his own efforts to increase the value of an investment, it is not a security for purposes of the Securities Act, subject to limited exceptions. ${ }^{160}$

When an investor contributes money to a DAO, he is relying on the smart-contract code to manage the funds and the chosen third-party service provider to pursue and complete the approved projects. ${ }^{161}$ The

152. Peter Van Valkenburgh, DAOs: The Internet is Weird Again, and These are the Regulatory Issues, COINCENTER (June 2, 2016), https://coincenter.org/entry/daos-theinternet-is-weird-again-and-these-are-the-regulatory-issues [https://perma.cc/4CJZPA79].

153. Brener, supra note 90.

154. Hinkes, supra note 93.

155. Id.

156. United Hous. Found. v. Forman, 421 U.S. 837, 852 (1975).

157. Id

158. Id.

159. See SEC v. Shields, 744 F.3d 633, 643-44 (10th Cir. 2014).

160. Exceptions to the general partner rule have been established to protect partners in limited circumstances. See Williamson v. Tucker, 645 F.2d 404, 424 (5th Cir. 1981).

161. Slock.IT, supra note 86. 
only involvement of the investor is voting on whether to approve a project, and investors are not required to engage in voting. ${ }^{162}$ Therefore, the investor is nothing more than a passive investor with voting rights in the organization.

It could be argued that because the investors have voting control over which projects to pursue, they are not relying on the efforts of others and are therefore partners in the enterprise. If the investors are in fact partners, U.S. courts and the SEC would make the presumption that an investment in a DAO is not an investment contract. ${ }^{163}$ This presumption may be overcome, however, by showing one of the following:

(1) An agreement among the parties leaves so little power in the hands of the partner or venturer that the arrangement in fact distributes power as would a limited partnership; or (2) The partner is so inexperienced and unknowledgeable in business affairs that he is incapable of intelligently exercising his partnership or venture powers; or (3) The partner or venturer is so dependent on some unique entrepreneurial or managerial ability of the promoter or manager that he cannot replace the manager of the enterprise or otherwise exercise meaningful partnership or venture powers. ${ }^{164}$

Although the investors in a DAO may have more power than a limited partner, and are therefore not solely relying on the efforts of others, as a whole they lack general experience and knowledge in the various projects proposed and are incapable of exercising their potential partnership powers. Because investors are dependent on the creators of the smart-contract, they cannot exercise meaningful power over the partnership. The creators of the smart-contract, with no input from the investors, have the power to create the terms of the contract and how the organization will operate, as well as when voting may be put on hold. ${ }^{165}$

\section{E. SEC Release No. 81207}

On July 25, 2017, prior to the publication of this Article, the SEC issued Release 81207 (the "Release"). ${ }^{166}$ The Release follows an investigation of The DAO pursuant to Section 21(a) of the Securities Exchange Act of 1934, and confirms that tokens issued by The DAO are securities. ${ }^{167}$ Although the SEC confirms that The DAO issued unregistered securities, the Release states that no enforcement action

162. See Hinkes, supra note 93.

163. See Williamson, 645 F.2d at 422-23.

164. Id. at 424.

165. See supra text accompanying note 112 .

166. Report of Investigation Pursuant to Section 21(a) of the Securities Exchange Act of 1934: The DAO, Exchange Act Release No. 81207, 17 SEC Docket 5 (July 25, 2017)

167. Id. 
would be taken against The DAO. ${ }^{168}$ The question though, is why not? Part VII addresses the implications of enforcing the current registration requirements against DAOs and proposes an amendment to the Securities Act.

\section{Vi. A Brief Overview of Current Registration REQUIREMENTS}

Prior to issuing securities, a company is required to conduct a financial audit and disclose information through registration. ${ }^{169}$ Depending on the size of the issuance, the disclosure of this information can be complex, costly, and time consuming. ${ }^{170}$ The company is required to hire an underwriter, auditors, accountants, and attorneys. ${ }^{171}$ It is estimated that the average cost of going public is $\$ 4.7$ million. ${ }^{172}$ In addition to the cost of going public, companies are required to file annual and quarterly reports, averaging $\$ 1.5$ million per year. ${ }^{173}$

These costs are attributable to the filing of a registration statement with the SEC. ${ }^{174}$ The registration statement requires the company to disclose a myriad of information, including but certainly not limited to risk factors, basic information about the business, information on the company's managers, and financial information. ${ }^{175}$

Some companies, however, are able to identify an exemption within the securities laws, thereby allowing them to sell securities without filing a registration statement. These exemptions require careful attention to detail, and in most cases, are unavailable to DAOs.

The two most common exemptions are private offerings and intrastate offerings. ${ }^{176}$ Regulation D is the safe harbor rule for a private offering, meaning that if a company decides to sell unregistered securities, compliance with the rule exempts the company from liability for failure to register the securities. ${ }^{177}$ The rule limits the number of nonaccredited investors that may invest, limits on the offering amount, and prohibits the company from soliciting investors. ${ }^{178}$ To comply with

168. Id.

169. Considering an IPO? \& The Costs of Going and Being Public May Surprise You, Strategy\&, https://www.strategyand.pwc.com/media/file/Strategyand_Consid ering-an-IPO.pdf (last visited Sept. 26, 2017) [https://perma.cc/T5EW-SANM].

170. Id.

171. $I d$

172. Id.

173. Id.

174. See Fact Answers: Registration Under the Securities Act of 1933, U.S. SEC. AND ExсH. Cомм'N, https://www.sec.gov/fast-answers/answersregis33htm.html (last visited Sept. 26, 2017) [https://perma.cc/V8ZH-EDF5].

175. Id.

176. Id

177. Fact Answers: Regulation D Offerings, U.S. SeC. And Exch. Comm'n, https:// www.sec.gov/fast-answers/answers-regdhtm.html (last visited Sept. 26, 2017) [https:// perma.cc/5GH8-22MV].

178. Id. 
the intrastate offering exemption, the company must be a resident and doing business within the state where the issuance occurs, and all investors must be residents of the same state. ${ }^{179}$ DAOs do not qualify for either exemption because, currently, they do not determine whether investors are accredited or residents of a particular state.

\section{The Future of DAOs Due to the Effects OF REgulation}

This Article argues that DAOs fall under SEC jurisdiction, which has been confirmed by the SEC. However, enforcement of the securities laws, as currently written, will result in the ultimate failure of DAOs. By enforcing the current regulations, someone must be held accountable for selling unregistered securities, and if someone is held accountable, the organization cannot be autonomous-there must be someone in charge and making the decisions. ${ }^{180}$ However, the capabilities of the blockchain and smart-contract used to operate DAOs may cause regulators to second-guess enforcing the costly registration requirements of the Securities Act. Perhaps the SEC is aware of these implications, as evidenced by their decision to not seek enforcement actions against The DAO after acknowledging the issuance of unregistered securities in Release No. $81207 .{ }^{181}$ For these reasons, this Section of the Article proposes a change to the current registration requirements of the Securities Act.

\section{A. Registration Requirements for Issuers of Securities}

The Securities Act states that "unless a registration statement is in effect as to a security, it shall be unlawful for any person, directly or indirectly ... to make use of any means or instruments of transportation or communication in interstate commerce or of the mails to sell such security through the use or medium of any prospectus or otherwise." ${ }^{182}$ The process of registering a public offering is not only time consuming, but also extremely expensive. ${ }^{183}$ Following the registration of securities are periodic filing requirements, which are also extremely

179. Intrastate Offering Exemptions: A Small Entity Compliance Guide for Issuers, U.S. SEC. AND ExCH. CoMm'N, https://www.sec.gov/info/smallbus/secg/intrastate-offering-exemptions-compliance-guide-041917.htm (last visited Sept. 26, 2017) [https:// perma.cc/8R8C-U7PK].

180. An argument that would take this Article down a different path is that because someone must be held liable, and because the investors are making some management decisions, such as which projects to pursue, they are not investors but actually partners within the organization. See Hinkes, supra note 93.

181. See supra note 166-168 and accompanying text.

182. The Securities Act of $1933 \S 5(\mathrm{a})(1), 15$ U.S.C.A. $\S 77 \mathrm{e}(\mathrm{a})(1)$ (Westlaw through Pub. L. No. 115-90) (2012).

183. The average expense for an IPO raising $\$ 0-50$ million is $\$ 4.7$ million. See Considering an IPO?, supra note 172. 
burdensome. ${ }^{184}$ Therefore, requiring a DAO to file a registration statement prior to issuing securities raises multiple issues.

The crowdsale used by DAOs to raise their initial capital is generally conducted immediately following the formation of the DAO. Because the Securities Act requires registration prior to the issuance of securities ${ }^{185}$ a DAO could not conduct a crowdsale until after a registration statement is filed and becomes effective. This creates a detrimental problem for DAOs. Prior to the crowdsale, a DAO has neither the time nor the funds to complete and file a registration statement, effectively causing a Catch $22-\mathrm{a}$ DAO cannot conduct a crowdsale until a registration statement is effective, but it cannot afford to file a registration statement until after a crowdsale (although many other factors will still prevent its ability to file a registration statement even if funding were not an issue).

The second problem with the registration requirements is the autonomy of token holders. The pillar on which DAOs and smart-contracts are built is anonymity. If the registration requirements of the Securities Act were imposed on DAOs, it would require someone to be held accountable for filing such registration statement, as well as accountability for the accuracy of the information provided during registration. Identifying a responsible party would destroy anonymity.

Finally, it must be determined who is responsible for the filing. Because DAOs are decentralized, no single person is in control. Therefore, does the responsibility fall on the creator of a DAO? Perhaps the miners who are keeping the blockchain operational? Another argument is that the token holders should be responsible. They are, after all, responsible for making all operational decisions for the DAO. After determining who is responsible for filing the registration statement, who is then responsible for certifying that the statements are correct? It would seem illogical to put this burden on token holders considering that, in most cases, investors are 1) generally not certified public accountants or executive level officers who have the required knowledge to make this certification; and,2) the offering and sale of securities occurs prior to the token holder's existence. Therefore, perhaps the strongest argument is that the responsibility should fall on the creator of a DAO. This is the most plausible argument considering this person writes the smart-contract and initiates the crowdsale; the other players do not enter the game until after the crowdsale.

For the sake of argument, assume it is the responsibility of a DAO creator to file the initial registration statement. Who is then responsible for filing periodic statements? At this point the DAO is under the control of the token holders through their voting power. Therefore,

184. See id.

185. See The Securities Act of $1933 \S 5(a)(1), 15$ U.S.C.A. $§ 77 e(a)(1)$ (Westlaw through Pub. L. No. 115-90) (2012). 
does this responsibility fall on them? Perhaps the solution to the problem could be written into the smart-contract? Similar to the provision designating a service provider, perhaps a third-party could be contracted to ensure the registration requirements are met. If this is the answer, who is responsible following a violation? The third-party? The token holders? These are all questions that must be answered under the current registration requirements and, again, the answers would likely destroy the foundation of the DAO and, subsequently, the intrigue that has attracted many investors.

Based on the foregoing analysis, it is clear that many issues must be resolved and the structure of the DAO must change under current registration requirements. However, because of the structure of DAOs, most of these issues cannot be resolved without destroying the foundation of these organizations. DAOs cannot financially operate without conducting a crowdsale, yet do not have the money to file a registration statement until after the crowdsale. Furthermore, as discussed, the entire framework of the DAO, which is the reason these organizations are appealing, would likely be destroyed following registration.

\section{B. Why Regulation is Necessary and Actions Taken by Congress}

As previously mentioned, the potential for loss based on the nature of the DAO is significant. ${ }^{186}$ Not only are investors exposed to the risk of hackers and technological problems, they are also at risk of the investment never returning a profit due to the lack of proposal approval. Beyond these uncontrollable risks is the looming question of whether DAOs are actually decentralized. The creators, after all, have the power to create and include any terms imaginable when writing the smart-contract. Additionally, the Ethereum founders have the power and control to cause a hard-fork in the system. ${ }^{187}$ While investors are free to accept these risks, the purpose of securities laws is to ensure disclosures are made regarding the offering of securities prior to investment. Most DAOs, specifically The DAO, have failed to make these material disclosures.

Therefore, to ensure disclosure, regulation is necessary. Without regulation, DAO creators may make material misstatements or omissions, thereby misleading investors. The DAO is a prime example. As previously discussed, The DAO told investors that there were no issues with the smart-contract operating the DAO, but there was in fact a recursive call located in the software, resulting in the exploitation of The DAO and the loss of $\$ 50$ million. ${ }^{188}$

186. See supra text accompanying notes $113,116$.

187. See Siegel, supra note 82.

188. See id. 
In September 2016, the U.S. House of Representatives acknowledged the need for blockchain regulation, although the investment risks of DAOs-nor DAOs in general-were specifically mentioned in the Bill. ${ }^{189}$ The Bill also recognized the potential benefits of the technology and, with appropriate protections, stated a belief that policy should encourage the development of the technology. ${ }^{190}$ The Bill calls for "a national policy ... [that] encourage[s] the development of tools for consumers to learn and protect their assets in a way that maximizes the promise customized, connected devices hold to empower consumers, foster future economic growth, [and] create new commerce and new markets." ${ }^{191}$ Congress has acknowledged both the usefulness and potential dangers of blockchain technology. It is unclear whether Congress is currently aware of or monitoring the use of blockchain technology for the creation of smart-contracts and, specifically, DAOs. As of the date of the publication of this Article, Congress has not moved forward with any policy proposals.

On a similar note, prior to the blockchain bill, Rep. Stockman (RTX) introduced a bill titled the "Online Market Protection Act of 2014."192 This Bill would have prohibited, for a period of five years beginning June 1, 2015, any regulation governing the "creation, use, exploitation, possession, or transfer of any algorithmic protocols governing the operation of any virtual, non-physical algorithm or computer source code-based medium of exchange (cryptocurrency)." 193 Although introduced over three years ago, the Bill has not moved beyond the House of Representatives. ${ }^{194}$

\section{Proposal for New Regulation}

As previously discussed, Blockchain technology is on the congressional radar. ${ }^{195}$ Any legislation passed to regulate blockchains must take into consideration the various methods in which the technology is used, including smart-contracts and DAOs. Beyond blockchain regulation, the current securities regulations must be amended. As the securities laws are currently written, DAOs are issuers of securities subject to the demanding requirements of the Securities Act, as acknowledge by the SEC. ${ }^{196}$ This Article proposes that, in addition to any regulations governing blockchains, which are beyond the scope of this Article, a new exemption to securities registration be introduced. This exemption must allow DAOs to operate in a decentralized and

189. See H.R. Res. 835, 114th Cong. (2016) (enacted).

190. See id.

191. See id.

192. H.R. 5892, 113th Cong. (2014).

193. Id.

194. See id.

195. See supra Section VII.B.

196. See supra Section V; see supra note 167. 
autonomous manner, yet provide the protection of disclosure to investors.

Congress has already acknowledged the usefulness of raising capital through a crowdsale, and in response passed Title III of the JOBS Act. Title III provides an exemption to registering securities offered through a crowdsale, given that certain criteria are met. ${ }^{197}$ However, the exemption in Title III, which drastically relieves a company of the burdensome registration requirements, is still too taxing for the unique nature of DAOs. Compliance with any of the current securities regulations would restrict a DAO from operating solely through a smart-contract as a decentralized, anonymous organization. For example, Title III limits the issuance of securities to $\$ 1$ million per 12month period. ${ }^{198}$ Limiting DAOs to such revenue restrictions would make operations financially infeasible, and would decrease the appealing nature of DAOs. Furthermore, Title III requires issuers to provide the name of both the issuer and the directors and officers. ${ }^{199}$ This requirement is impossible to satisfy due to the decentralized nature of a DAO and the lack of directors and officers. If DAOs were required to appoint directors and officers to comply with the statute, followed by the release of such officers' and directors' names, anonymity and decentralization would be destroyed.

To prevent the destruction of DAOs through the burdensome requirements of registration, this Article proposes a new exemption to regulation for the issuance of tokens through DAOs. The autonomy of investors must be preserved. The exemption, therefore, must be carefully drafted to preserve anonymity and decentralization. Additionally, limits on the issuance amount should be avoided. Currently, the only method used by a DAO to raise capital is a crowdsale. Limiting the amount of capital raised through the crowdsale would suffocate a DAO and destroy the concept. Any exemption, however must include two requirements: 1) a fiduciary duty must be placed on the creator of a DAO; and, 2) all DAOs must make certain disclosures.

\section{Responsibility for Required Disclosures}

As previously discussed, DAOs are issuers of securities, and the Securities Act requires such issuers to file a registration statement containing specific disclosures. ${ }^{200}$ Through such disclosures, however, a $\mathrm{DAO}$ is at risk of failure due to the loss of anonymity and decentrali-

197. Press Release, U.S. Sec. and Exch. Comm'n, SEC Adopts Rules to Permit Crowdfunding (Oct. 30, 2015), https://www.sec.gov/news/pressrelease/2015-249.html [https://perma.cc/22JC-RQEL].

198. Jumpstart Our Business Startups Act $\S$ 302(b)(b), 15 U.S.C.A. $\S 77 d(a)(6)(A)$ (Westlaw through Pub. L. No. 115-90).

199. Jumpstart Our Business Startups Act $\S 302,15$ U.S.C.A. $\S 77 d(d)(3)$ (Westlaw through Pub. L. No. 115-90).

200. See supra Sections VI \& VII.A. 
zation. To prevent the potential destruction of DAOs while ensuring that investors are informed, this Article proposes that an exemption be passed to relieve DAOs of the burdensome registration requirements. Through such exemption, a temporary fiduciary duty should be imposed on the creator of a DAO to ensure certain disclosures are made prior to the issuance of tokens.

Following the creation of a DAO, but prior to the crowdsale, only one individual or entity has complete knowledge of, or the ability to obtain knowledge of, all the provisions of the smart-contract codethe creator of the DAO. The Ethereum website states: "an Owner [or creator] . . . works like an administrator, CEO or a President." ${ }^{201}$ The creator has the power to write the terms within a smart-contract, and the ability to identify potential problems within the code of the smartcontract. Because of this combination of knowledge and power, the creator of a DAO must bear the burden of making certain disclosures.

The Author acknowledges that such disclosures will require a certain loss of anonymity. The loss, however, is minimal and limited to the creator of the DAO, which is already disclosed in some instances. ${ }^{202}$ Still, the proposal that a fiduciary duty be placed on the creator carries a significant level of responsibility, and therefore deserves justification.

First, the creator has the power to write the smart-contract code. This allows the creator to determine, among other things, exactly how the DAO will operate, who the initial third-party service provider will be, how voting will occur, and how much voting power token holders are given. Furthermore, the creator has the power to issue himself equity tokens prior to the crowdsale. Token issuance, combined with the power to write the terms of the smart-contract, gives the creator the potential power to determine whether any future proposed projects will be approved or denied. For example, if the creator issues himself $51 \%$ of the total authorized tokens and includes a provision requiring a majority vote in favor of a project for approval, the creator has given himself complete control. Investors should know, prior to investing, that a single token holder has majority control.

Second, the creator has the ability to detect problems within the code. ${ }^{203}$ Absent the disclosure of a problem and the failure to correct it, token holders are at risk of significant loss. Disclosure must be made to 1) allow an investor the opportunity to make an informed decision; and, 2) allow a token holder the opportunity to sell his tokens if he determines the risk is too high. This disclosure and ability to make an informed investment decision is the premise of securities laws.

201. How to Build a Democracy on the Blockchain, ETHEREum, https://www.ethereum.org/dao (last visited Sept. 26, 2017) [https://perma.cc/B9V7-YBKE].

202. See Siegel, supra note 82.

203. See id. 
Based on the unique position of the creator, combined with the power and ability to access all relevant information pertaining to the $\mathrm{DAO}$, a duty to disclose information to potential investors and current token holders must be imposed on the creator.

\section{Required Disclosures}

Although this Article proposes an exemption to the current registration requirements, new regulations must require the disclosure of certain key information. Such information will provide investors with the minimum knowledge needed to make an informed investment decision. Though slightly burdensome, the limited disclosure requirements should be financially and administratively feasible for DAOs to collect and disclose.

\section{a. Disclosure of the Creator's Name}

An exemption to the current registration requirements must require the disclosure of a DAO creator's name. As previously discussed, DAO creators should owe a fiduciary duty to investors. ${ }^{204}$ Therefore, because the fiduciary duty requires the creator to disclose certain information, the SEC and investors must know the creator's name. Requiring the disclosure of the creator's name allows an individual or governmental entity to pursue a cause of action when an issue arises, thereby ensuring the fiduciary duty of the creator is upheld. The exemption, however, should be written to ensure that only the name of the creator is required to be disclosed. Failure to carefully draft this provision may result in the destruction of anonymity beyond what is necessary.

\section{b. Disclosure of the DAOs Purpose}

Prior to investing, potential investors should be informed of the purpose of the DAO and the types of projects it may be pursue. Regulations, however, should not limit the possible purposes a DAO may pursue. For example, if the purpose of a DAO is to pursue any variation of possible projects within a specific field, regulation should not prevent such purpose, so long as that purpose is disclosed to the investor. Because of the decentralization of DAOs, and the ability to build a DAO that allows investors to choose its direction, some DAOs may not have a specific purpose at the time of the crowdsale. Such specific purpose may later be determined by the investors.

Most DAOs, however, have an overarching, general purpose in mind when created. ${ }^{205}$ Although the purpose may not be specific, the

204. See supra Section VII.C.1.

205. Examples may include maintaining travel records and documents on a blockchain. See EthPassport, GiтHuB, https://github.com/mdcuesta/EthPassport (last visited Mar. 10, 2017) [https://perma.cc/5TQ2-6CP3]. 
general idea must be disclosed. For example, the capabilities of the selected third-party service provider may be limited to certain projects, thereby limiting the types of projects that may be pursued, or the smart-contract may be written in a manner that focuses on a general type of project. Because capabilities of the third-party service provider may be limited, or the terms within the smart-contract limit what the DAO may do, investors must be informed of these specific limitations and a broad "any lawful purpose" may not be given as the DAO's purpose.

The goal in requiring the disclosure of a DAO's purpose is not to protect the investor from making a bad investment decision, but to ensure the investor is given the information needed to make an informed investment decision. If given this information, the investor is then responsible for deciding whether to move forward, regardless of whether the investment decision is wise.

\section{c. Disclosure of the Smart-Contract's Terms}

A DAO must be required to disclose all terms within the smartcontract. Given the nature of the DAO, and the promise of decentralization, investors have a right to be informed about the smart-contract terms. These terms control everything the organization may do, and how those things will be done. For example, if the smart-contract includes a term requiring a supermajority vote for the approval of a proposed project, the requirement must be disclosed to investors. A supermajority vote will limit the number of projects approved, thereby potentially limiting the return on investment. Additionally, if the terms within the contract give the creator majority control of the $\mathrm{DAO}$, and majority control is required to approve or reject a project, the investors have a right to know this information prior to investing. Based on the terms of the contract, investors may ultimately be given little to no voting power. Therefore, the terms of the smart-contract must be disclosed to ensure investors are given the opportunity to make an informed investment decision.

\section{d. Third-Party Service Provider Disclosure}

The third-party service provider written into the smart-contract code must be disclosed to investors. Investors should be informed about the individual or entity that will ultimately be responsible for implementing projects, following approval by token holders. This disclosure allows the investor the opportunity to research the service provider to determine their sustainability, reputation, and ability. For example, an investor may choose to not invest if the purpose of the $\mathrm{DAO}$ is to pursue projects that will promote sustainable energy, and the third-party service provider is an expert in coal-mining projects. For this reason, the name of the third-party service provider must be disclosed prior to investing to allow the investor an opportunity to 
research the service provider and determine whether it can support the projects projected to be pursued by the DAO.

\section{e. Disclosure of Risks}

Like a traditional corporation, DAOs should be required to disclose all material risks associated with the DAO prior to the crowdsale. This information, like other disclosures, gives the investor the opportunity to make an informed investment decision.

A DAO must be required to disclose both the potential risks of a DAO in general, as well as the risks specific to each DAO. General risks may include the possibility of hacking or a project never being approved, thereby preventing the investor from ever receiving a return on investment. Specific risks may include the risks associated with the purpose of a DAO. For example, if the purpose of a DAO is to pursue sustainable energy projects, the risks associated with sustainable energy projects must be disclosed.

The purpose of regulation is not to prevent a DAO from pursuing a certain type of project, but instead to inform the investor of the potential risks with such purpose prior to investing. If a DAO is overflowing with potential risks, that is acceptable, so long as those risks are disclosed to the investor.

Initial disclosures of risks and other material information, however, are insufficient. Comparable to the required 8-K filing for a traditional corporation, ${ }^{206}$ DAOs must continuously disclose information that may be material to an investor, thereby allowing the investor to continuously make informed investment decisions. For example, when the recursive call was found in The DAO, investors should have been informed of both the problem and the risk that The DAO may be hacked. Instead, The DAO informed investors of the problem, but misled investors into believing that their funds were safe. This failure to disclose material information resulted in substantial losses for many investors. Continuous disclosures will give the investor an opportunity to make an informed decision and to take appropriate action regarding the investment.

Responsibility for continuous disclosure is a potential issue. Unlike prior to the crowdsale, the investors now have voting control over a DAO and the creator is not necessarily the "person in control." As discussed later in the Article, ${ }^{207}$ the creator should be given the power to shift this burden, although the terms of such shifting, prior to its occurrence, must be disclosed to the investors.

206. Public companies are required to disclose any major events that may impact a shareholder's investment decision by filing an 8-K. See Form 8-K, U.S. SeC. AND ExсH. Coмm'N, https://www.sec.gov/fast-answers/answersform8khtm.html (last visited Feb. 1, 2018) [https://perma.cc/FF5U-SHNH].

207. See infra Section VII.C.3. 
The Author acknowledges the financial barriers associated with risk disclosures and welcomes discussion regarding how to ensure risks are disclosed without subjecting DAOs to such burdensome cost requirements.

\section{f. Financial Disclosures}

Along with the continuous disclosure of material information, DAOs must be required to file annual financial reports. This information should include, among other general financial disclosures: any funds obtained through secondary crowdsales; the number of tokens issued to the creator, investors, and miners; projects that have been approved or denied and funds used to pursue approved projects; and the funds used to pay the third-party service provider. This annual reporting will keep investors informed about the projects being pursued by the DAO and whether those projects are providing a return on investment, as well as whether their token ownership has been diluted.

\section{Disclosures Following the Crowdsale}

As noted in the previous Section, new regulations must require continuous disclosure throughout the life of a DAO. This presents a potential problem and deterrent effect for the creator of a DAO. It is unlikely that a creator will want to subject himself to the endless responsibility of reporting or the significant fiduciary duty associated with the creation of a DAO. Therefore, the creator of a DAO should be allowed to shift this responsibility to a third-party following the initial crowdsale.

Similar to the third-party service provider, new regulations should allow for the designation of a third-party who is responsible for all required disclosures subsequent to the crowdsale. Just as the creator has a fiduciary duty to investors during the initial disclosures, the third-party must owe a fiduciary duty to investors.

The shifting of this duty presents two issues: 1) this type of thirdparty provider who assumes responsibility for financial and risk disclosures does not exist; and 2) because accepting this duty is extremely risky, it is unlikely that individuals or businesses will step forward to take on this role.

Given the opportunities blockchain and DAOs present, the Author argues that allowing this burden to shift to a third-party opens the door to a new industry. Although these third-parties do not yet exist, blockchain did not exist a few years ago either. New regulations allowing the creator to step away from the DAO and give control to investors, who will then have control over the third-party, is a very enticing prospect. Creators of DAOs will likely be willing to encourage the emergence of this new industry and pay fairly for the re- 
lief of reporting duties. The regulations and specific details of this new third-party fiduciary are beyond the scope of this Article, but the Author wants to bring attention to the fact the possibility of burden-shifting is an option for these new, complex organizations, and argues that new regulations should allow for this option.

\section{CONCLUSION}

While the risks associated with the smart-contracts and DAOs are serious, both provide for the use of cutting-edge technology with the potential for technological advancement in many industries. ${ }^{208}$ Transactions that currently require the use of multiple intermediaries and paper trails could be replaced by a much more efficient smart-contract. ${ }^{209}$ Absent an applicable exemption, however, DAOs are currently subject to regulation under the Securities Act. Investors have a right to full disclosure prior to making an investment, but the current regulations regarding this disclosure will destroy the foundation on which DAOs are built and the intrigue that pulls in new investors. ${ }^{210}$ Therefore, a new exemption to regulation must be created. This exemption to regulation, however, must also prevent the DAOs from making material omissions or misstatements. Otherwise, the investors can easily be taken advantage of when deciding whether to invest. Therefore, Congress must impose on the creator of a DAO a fiduciary duty to disclose material information and require that certain information unique to DAOs is disclosed. Additionally, limited disclosures common to all public entities must be made to ensure investors have the opportunity to make an informed investment decision. Finally, Congress should consider the allowance of burden shifting following a DAOs initial crowdsale, and encourage the creation of this new industry.

208. See supra text accompanying note $20-24$.

209. See supra text accompanying notes 24 .

210. The Laws that Govern the Securities Industry, supra note 131. 
